\title{
Language and Nature in Southern and Eastern Arabia
}

\author{
Kaltham al-Ghanim \\ Qatar University \\ Janet C.E. Watson
}

University of Leeds

\section{Abstract}

This paper examines the relationship between language and nature in southern and eastern Arabia. The work is the result of a two-year interdisciplinary network between the University of Leeds and Qatar University, with partners in the UK, Oman, Canada, the United States, and Russia. Our hypothesis is that local languages and ecosystems enjoy a symbiotic relationship, and that the demise of local ecosystems will adversely affect local languages. In this paper, we examine some of the language-nature effects in Qatar and Dhofar, southern Oman. Our regions differ in that Qatar has two seasons, summer and winter, and is predominantly arid, with occasional rain, while Dhofar together with al-Mahrah in eastern Yemen has four distinct seasons, receiving the monsoon rains between June and September, and, as a result, is home to hundreds of plants and animals found nowhere else in the world. Since the 1970s, in particular, both regions have experienced some of the most rapid socio-economic changes in the world. We ask what affect this socio-economic change has had on the language-nature relationship, and suggest that decoupling of the human-nature relationship as a result of socio-economic change is contributing in these regions to language attrition. We consider spatial terminology, traditional terminology for weather, the traditional measurement of time by narratives around key climatic events, and the role of stars in determining the weather and their role in folklore. *

Keywords Arabic, Qatar, Modern South Arabian, Dhofar, nature, weather, time, climatic events, stars, spatial reference

\footnotetext{
* We thank our funders, the AHRC for a network grant to study the symbiotic relationship between language and nature in southern and eastern Arabia (2017-2019), and our consultants in Dhofar and al-Mahrah: Saeed al-Mahri, Nwēr Muhammad Bakrayt, Saeed al-Awaid, Khalid Ruweya al-Mahri, Ali al-Mahri and Abdullah Musallam al-Mahri.
} 


\section{Introduction}

Language and nature have a tight symbiotic relationship, particularly in regions of the world such as Qatar and Dhofar in which people have until recently enjoyed a close relationship with the natural world. New research approaches are now emerging that relate language and ecology in a way that provides better understanding of humannature-language relationship. This paper addresses the disappearance of endangered languages and their related cultures, and also the loss of indigenous cultural knowledge due to dialectal loss. Studies suggest a strong correlation between the decline in language diversity and environmental diversity (e.g. Rosenthal 2014), which is further evidenced by WWF studies. Part of our work involves the collection and analysis of intangible heritage; however, the collection of intangible heritage is not designed to be an end in itself: intangible culture encapsulates local knowledge, and reinforces the relationship between humans and their ecosystems.

The languages spoken in our regions are Qatari Arabic, with its various sub-dialects, in Qatar, and the Modern South Arabian languages and the language of Bayt Kathir in Dhofar, all of which are endangered. In section 1 of this paper, we begin with a brief introduction to the languages and the degree of socio-economic change in the region. In section 2, we consider language erosion factors, and how erosion of the natural environment and the relationship people have with the environment can precipitate language loss. In section 3, we examine the language-nature relationship focussing on terminology around weather, and then the measurement of time around key climatic events. We conclude with some suggestions for capturing aspects of the language-nature relationship while we still have access to people who have experienced the pre-motorised past.

\section{The Languages}

The language spoken in Qatar is Qatari Arabic, with dialect distinctions according to region and tribal affiliation. Despite Arabic being an important language with over $300 \mathrm{~m}$ speakers (reference), Arabic dialects have been facing major challenges since the mid-20 $0^{\text {th }}$ century due to the growth of the media, film, music, and the influence of other languages through actual and virtual language contact. Preserving indigenous dialect vocabulary has become important in itself and also to preserve local knowledge. Examples of Qatari dialect disappearing in younger generation.

The languages traditionally spoken in Dhofar are four of the six Modern South Arabian languages (Johnstone 1981, 1987; Rubin 2010, 2014, 2018; Watson 2012), Mehri, Śherēt (also known as Jibbali), Hobyot and Bathari, and the Arabic variety spoken by Bayt Kathir, which shares lexical and grammatical features with Modern South Arabian. Of the Modern South Arabian languages, Mehri is spoken over the largest area, spanning eastern Yemen, southern Oman, and reaching into southern and eastern Saudi Arabia; Śherēt is spoken in the mountains and coastal regions of Dhofar; Hobyot is spoken in a small area spanning the Yemen-Omani border; and the few Bathari speakers are based around the coast of eastern Dhofar. Mehri, Hobyot 
and Śherēt have a number of distinct dialects according to tribal affiliation and geographical region.

The Modern South Arabian languages (MSAL) have no traditional script and constitute the most endangered sub-family of Semitic languages, ranging on Ethnologue (an authoritative resource on world languages) from 'nearly extinct' to 'shifting'. Speaker numbers are 12 (Bathari), 1,000 (Harsusi, Hobyot), 30,000 (Shehret), 60,000 (Soqotri), 200,000 (Mehri). The precise number of speakers is, however, impossible to ascertain: there are no census figures relating to MSAL speakers specifically, and many members of the language communities no longer speak the languages fluently or at all. Since the 1970s, the spread of Arabic has meant that the MSAL have increasingly fallen into disuse. This has been hastened by rapid social change and the collapse of traditional cultural activities.

In both Qatar and Dhofar, people were almost entirely reliant on themselves and their wider tribal affiliations until the 1950s and 1970s respectively, when the modern states of Qatar and Oman began to be constructed. The Qatari natural environment system comprises, in addition to oil and gas, a geological structure of the land resulting in a shallow depression in which rainwater gathers, enabling wild plants and shrubs to grow. These depressions are fertile and give rise to an arable land environment, suitable for various kinds of native plants. The marine environment is also distinctive for its diversity, with numerous species of fish as well as coral and reefs and oysters. The best-known pearl fisheries in the Gulf and in the world lay opposite to the eastern coast of Qatar (General Secretariat for Development Planning 2009). Today no pearl fishing is conducted and very few Qatari nationals practise fishing for local commercial purposes.

Until the 1970s, there were were very few state-run schools or hospitals in Dhofar, transport was by foot, by pack animal or by boat, water was collected by foot from natural sources, and people lived in caves and brushwood or stone huts they constructed themselves. Life continued through extremely tight organisation of local activities and close monitoring of local weather and climate conditions. Today the region enjoys all the trappings of the modern age. Younger generations no longer have or understand the extensive knowledge and practical skills of their elders and much earlier expertise has been lost or is disregarded, with imported alternatives replacing locally manufactured items. Traditional methods of natural resource and water management are no longer passed on to the next generation, and significant degradation of the environment has occurred, with overgrazing and mismanagement of increasingly scarce water supplies, accompanied by severe overfishing. One result is that plants and animals that once played a vital role in everyday life are now extinct or rare.

\section{Erosion of Language and the Environment}

Language erosion in many parts of the world has been precipitated by social change, the collapse of traditional cultural activities, and a break with the relationship people 
have with the natural environment. We can see this in English, where modernisation, urbanisation and mass communication has resulted in dialect terms for alleys, for example, losing currency with regional-specific terms such as chare, vennel, jiggers, snicket, pends, ginnel, twitchel and terms for different types of alleys being replaced by general and superregional cover terms (Macfarlane 2015). Classical Arabic had a plethora of terms for 'to go' at various times of day and for various purposes, as is traditionally the case for the Modern South Arabian languages spoken in Dhofar, Soqotra and al-Mahrah (Watson \& al-Mahri 2017; Morris, Watson et al 2019); in Modern Standard Arabic, 'to go' is predominantly expressed by the cover term $\underline{d} a h a b a$ with an adverbial phrase to express the time of day or manner of travel; in the languages of Dhofar and al-Mahrah, precise traditional verbs of movement such as Mehri agōməś 'to go before dawn', ġsūm 'to go at dawn', ghēm 'to go in the morning', ahhawgar 'to go in the heat of the day', šūgūss 'to go from mid-afternoon', aśśôfak 'to go before sunset', abōssar 'to go in the light of the evening' and bār 'to go at night' (Morris, Watson et al 2019) are no longer used by the younger generation, who revert to a general cover term for 'to go' (ghēm or syūr in Mehri, ag் $\bar{a} d$ in Śhererz̄t) together with an adverb relating to time of day or manner of travel.

Qatar has a rich tradition of indigenous knowledge about the seasons, local weather and astronomy, but much of this folklore is rapidly disappearing because of fast economic and social change and the consumer culture that has resulted from economic and cultural change. The Qatari aim of the project is to collect and classify Qatari knowledge of seasonal events of local weather and the local systems of time keeping and navigation by the stars and creating a comprehensive lexical vocabulary of dialect terms, phrases and concepts of this heritage. Much of this vocabulary is not understood by young Qatari people today, so it is important to preserve it while there are still older individuals who retain this knowledge. As an example, one of the key astronomical systems used in the Gulf and on the Arabian Peninsula was the system of star markers known as anwa' or manazil al-qamar (lunar stations), known with variations throughout the region as well as in the formal Islamic science of astronomy (Varisco 1989, 1991, 1997). This lunar zodiac complemented the solar zodiac and was widely used to determine timing of seasonal events. The $a n w a$ 'star calendar was especially important for determining stages of date palm cultivation, seasons for pearl diving, fishing of particular types of fish, travel by sea, and expected periods of wind and rain, aspects of life which still very valuable for sustainable development today.

Evidence of the importance of dialect terms relating to the weather and seasons is indicated by one of the most important publications in Qatar's past, the Qatari Almanac of Sheikh al-Ansari. This almanac was widely known throughout the Gulf. In addition to providing a calendar for religious and seasonal agricultural and seafaring purposes, this almanac reflected local knowledge of the weather and the use of stars as markers of seasons (Varisco 1991). In the past, knowledge of movements of the stars, moon and sun were important for survival and in the various modes of production. Local dialects often used names of stars common to Arabic generally, but 
each dialect also developed names and expressions specific to the dialect. This is one reason why it is so important to document these local variants, many of which have never been recorded but still are in use in spoken dialects. We will examine more about the importance of the traditional Qatari lunar system under section 3.2 below.

Figurative language is closely engrained into the natural environment (Macfarlane 2015): cross-linguistically, expressions of beauty relate to what communities of speakers find beautiful in nature: in San'ani Arabic, a young girl is described as xadra 'green' due to her freshness, where 'green' in English would traditionally be interpreted as naive; in English, beauty is associated with spring in relation to the cold of winter, or to the warmth of summer, as we see in Shakespeare's 'Shall I compare thee to a summer's day?' (Sonnet 18). The positive connotations encapsulated in Mehri rwā $\dot{g} \bar{a} b$ 'branch [diminutive]' in Dhofar are taken to describe a young woman with height, slenderness and freshness, in bōkar 'young female camel' to describe a good-looking, fit young woman, in gazyerōt 'little old milking animal' to describe a woman affectionately, and in kayṣ́ar 'leopard' to describe a man of renowned bravery and strength. In Dhofar, where the sea breeze brings much relief during the hotter months preceding the monsoon period, the Mehri term mdit 'sea breeze', with its diminutive $m d \bar{\varepsilon} n \bar{t}$, plays a large role in poetry, contrasting with the searing heat of the $x r u \bar{b} b$ wind. Figurative language may in turn induce grammaticalisation (Palmer 2002), and in Bedouin societies we see grammaticalisation of terms relating to 'track; footprint' into a mirative particle with the sense of 'it transpired that'. Thus, Mehri śaff, Śherēt ścf'track; footprint' has been grammaticalised into the mirative particle śaf 'it transpired that' in Mehri, ścfin Śherēt (Watson \& al-Mahri 2017), and Arabic ?atr 'track; footprint' has been grammaticalised to, for example, tar 'it transpired that' in several Bedouin Arabic dialects. One of the effects of erosion of the relationship people have with their natural environment is that younger speakers are no longer in a position to understand aspects of traditional figurative language. When discussing śff in Śherēt with a younger member of the Śherēt-speaking community two years ago, she asked whether the term was derived from sof 'hair'. Watson's language consultant, Ali alMahri, explained that as the girl now lives in an urban, asphalted environment, she would not encounter tracks and therefore would not come into contact with the term śef'track; footprint'.

In Qatar and Dhofar today, we are in a position to observe the effect erosion of the human-environment relationship is having on language at the present time, and we are still able to record speakers who retain knowledge of the traditional systems. In section 3, we consider some aspects of the language-nature relationship, examining first spatial reference, then terminology around weather, and finally measurement of time through climatic events. 


\section{The Language-Nature Relationship}

The closer the relationship between people and the natural environment, the more linguistic expressions in the local languages refer to the environment and/or reflect the human-environment relationship. In our regions, the language-nature relationship is particularly evident in spatial and temporal terms, and in terms relating to weather and the climate, as these are essential factors in the life of peoples who are either nomadic or live from the land and livestock.

\subsection{Spatial reference}

The Modern South Arabian languages of Dhofar employ absolute spatial reference terms which correlate with topographic variation (Watson \& al-Mahri 2017). Younger generation speakers are said by our consultants to generally recognise and employ the traditional latitudinal terms, but to replace the longitudinal terms by Arabic šimāl 'north' and janūb 'south'.

For latitudinal reference terms, salōt or nșurêt refers to the direction of the rising sun, and kabalét the direction of the setting sun in Śherēt; these correspond to nșarāat and kablèt in Mahriyōt, the Mehri dialect spoken in Hawf in eastern Yemen (Nwēr Muhammad Bakrayt, p.c.), and məśkayṣ and kablēt or mārēb mārīb in the Mehri dialects spoken in Dhofar. Of these terms, three refer to fixed geographical locations: salōt 'the eastern region of Dhofar', kablēt (kabalét) 'the Qibla', and mārēb mārēb 'Ma'rib' or 'the Ma'rib dam'.1 For longitudinal reference, terms differ according to language and place of the speaker. In the mountains, the Jarbeeb (the coastal plain) and the town of Salalah, Mehri rawram 'sea', Śherēt ramnəm, describe a general southerly direction, and Mehri nagd 'Najd', Śḥerēt fagar 'stony desert' general north (Saeed al-Mahri, p.c.). Around the port town of Taqah and to the south of the mountains, Śherēt remnam 'sea' indicates general south, and śh̨r 'mountains' general north. In the mountains, fagar 'stony desert' indicates general north (Saeed al-Awaid, p.c.). More commonly, longitudinal directions are described in terms of the direction of the flood waters: $u$-mșa? (<lo-mșa?) in the Mehri varieties spoken in Central Dhofar denotes the direction in which the flood waters run, and hak, l-hak the direction from which the flood waters emanate. To the desert-side of the mountains, $u$-mșa? roughly indicates 'north', since the flood waters flow in a northerly direction, and seaward of the mountains, mșa? roughly indicates 'south'. Such differences in spatial reference terms that correlate to topographic variation, irrespective of how closely related the language varieties are, are found in other regions of the world in which languages have systems of absolute spatial reference (Palmer 2015; cf. also Rowley 1980 for Tirol; McKenzie 1997 for Sulawesi; Palmer 2002 for Oceania). The cultural importance of these terms is reflected in a common Mehri saying: falān yəáörab umșāe man l-ḩak lā 'so-and-so doesn't know downstream from upstream'. We are now

\footnotetext{
${ }^{1}$ In San'ani Arabic, gibli refers to the north and Sadanī 'towards Aden' to the south (Watson 1993). In Faifi, spoken on the Saudi side of the Saudi-Yemeni border, šămin 'Levant' refers to north of the Faifa mountains and yamanin 'Yemen' to south of the Faifa mountains (Alfaifi 2016).
} 
in a situation in the region where the younger generation does indeed no longer know the difference between downstream and upstream.

\subsection{Weather}

Terms for weather are traditionally very precise in our regions. In Dhofar and alMahrah, winds are described according to the direction from which they come and their severity. Thus, in Mehri alongside the general terms for winds, hazēz and rìyēh, there are the more precise terms depending on the source and severity: mdit 'sea breeze', zafzōf d $\underline{d} \partial-m d \bar{t} t$ 'perpetual sea breeze', xrūb 'hot desert wind', xrūb tōrab 'blasting hot desert wind', blēt 'wind from the north' and blèt šammamyat 'severe north wind'. Terms for weather temperature include habūr 'cold', kāṣam 'cold', hawb 'warm', hark 'hot', wakt 'humid', of which habūr 'cold', hark 'hot', wakt 'humid' also have verbal forms: haybar 'to feel cold', hayrak 'to feel hot', wakt 'to feel sticky from humidity'. The sharp, dry cold of winter, habür, will be described as making the liver

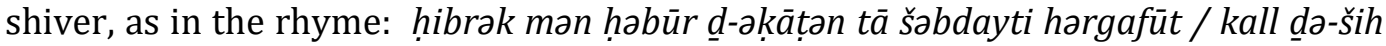
sabỉgat lā yahțāb aganzafüt 'I was so cold on the Qatan plain that my liver shivered / Anyone who does not have an indigo wrap should fetch a tree trunk (for firewood)'.

Qatar has a rich tradition of indigenous knowledge about wind due to the importance of the wind in determining seasons, transitional movement, sailing, and agriculture, and there are many items of vocabulary and synonyms that include knowledge about the wind. These terms circulated orally contain local knowledge on which people have been building their information and making their decisions about it, for example a set of words used by divers in the past revolve around the consonantal root $w-l-m$. The wind could be walam, which meant something that is perfect. In Classical Arabic, walam corresponds to the perfection of a thing: when the wind is walam it is suitable for sailing, and addition of the word hawa' 'wind; air' expresses the appropriateness of the direction of wind more accurately. With the introduction of mechanization and technology and the demise of traditional sailing ships, the directions of the wind are no longer of significance for seafaring. The winds do, however, still affect human life and link to the seasons for agriculture and movement of livestock.

The southern wind in Qatar is described as silli, and if it blows, people will say 'our wind today is sili', describing a light wind suitable for raising the sails. Silli may be related to the word sayl, which is the flow of water down the wadis, and if the clouds are dense people talk about 'clouds of siliyah'. Indeed, there is an area in Qatar called Silliyyah due to the presence of a large valley which attracts floods. The šamälīyah wind is cooling and comes at the end of the winter as summer approaches. The wind is described as lāhüb if it blows during the period of 'the boars', because it is hot and active and provokes dust. It is often hot because it comes from the desert and is described as 'hayfiyah', i.e. warm. When the wind comes from the south-east, it is called nakbah, a wind that people look forward to because it carries moisture and rain. The eastern wind is described as kaws, and the north-east wind is described as naYši. 
Al-bawärih 'the ominous' are hot north winds that occur in the summer months of June and July, ending around July 28.

Some winds are associated with folktales. In Qatar, the period between March 8 and April 2 is characterized by a strong, cold northerly wind that follows a period of warmth. This is called darbat al-\{ajūz 'the blow of the old woman'. According to tradition, an old woman decided to shear the wool of her sheep when she felt warm. After shearing the sheep, a cold north wind blew up killing the sheep, and so that wind has come to be described as 'the blow of the old woman'. The saying and the tale are used when alerting people to the oblivious. If someone says, 'The cold is over', the response will be, 'Don't act like the old woman who shore her sheep.'

\subsection{Climatic events and stars as a measurement of time}

\subsubsection{Dhofar}

Traditionally in Dhofar calendrical dates were not used to refer to events such as birth, death and marriage. In place of specific dates, reference would be made to particular climatic events (al-Manji \& Watson 2019). Climatic events of particular significance in this region include §ōnat $\varepsilon$-kamro 'the year of the people from Jabal Qamar', which refers to the year (around 1951) in which the effects of the drought were so severe that people left the region and headed east, snet $\underline{d}$-əlhaymar 'the year of the post-monsoon cyclone' (1947), snèt d-agarkāayat 'the year of drowning' (1959), when the pre-monsoon cyclone resulted in the capsizing of two large vessels off the coast of Dhofar with huge loss of life, and snèt da-bit fargiss 'the year of the Fargish family' (1963), when the whole Fargish family were swept away in a flash flood. In relation to these events, older people will describe being old enough to milk a camel at that time, or that they had just married, or that they were just old enough to remember.

\subsubsection{Qatar}

In our region, the year was divided into major seasons according to changes in climate, and historical events, agriculture and mobility were linked with particular stars. In this section, we mention a few stars and their association with particular events or agricultural activities.

Local dialects often use common star names in Arabic, but each dialect also developed its own specific names and expressions, such as the star širri, the brightest star in the sky. The people of the Arabian Gulf call it tair and the people of the Najd region of the Arabian Peninsula call it al-murazzam, as in Qatar and most of the Arab Gulf communities. This star is associated with the fruiting of the ratab dates and the

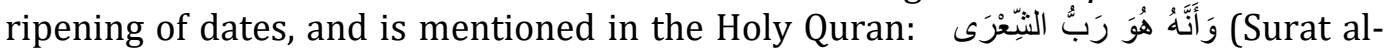
Najm: 49). Here and elsewhere, seasonal knowledge overlaps with religious knowledge. Many adages relate to this star and its association with agriculture, especially date cultivation, as well as other religious and metaphysical meanings. 
Al-na\{ā'im consists of eight stars, which form the shape of an archer (Sagittarius), composed of two rectangles, slightly distorted. The star of the southern arch shines in the lower rectangle, and in the upper rectangle the star nunki. Entry time: The sun descends outwardly from January 15, to the end of January 27, the fourth period in winter. Al-nåä'im is associated with a cold northerly wind. According to the popular adage, 'al-nafā'im awakens the sleeper', so said because people are unable to sleep due to the severity of the cold.

Al-sarìyāt brings about a sudden change in the weather, beginning on March 20 and ending on July 21, the transitional period from spring to summer. The weather during this period is characterized by thunderstorms accompanied by strong and often destructive winds. This weather behaviour occurs from time to time, often at night, and the root of the term sarīyāt appropriately relates to movement at night.

Al-țrayā (Thuraya) appears from June 7 to June 19, and is the most famous star cluster, consisting of six visible stars, while those with strong eyesight are said to be able to see seven. The viewing of the thuraya cluster begins in the morning (with yellow before sunrise) on the eastern side on June 7 and the appearance of the thuray $\bar{a}$ star marks the beginning of the season for harvesting dates.

\section{Conclusion}

Language enjoys a close relationship with the natural environment, particularly within regions where people share their everyday lives with nature. This relationship can be seen in the lexis of a language and the ways in which people describe spatial features and temporal events. Qatar and Dhofar until the very recent past were regions in which people made, gathered, farmed or bartered materials for food, water, shelter, tools, medical treatment and clothing. Today no one relies entirely on the land or on the sea, and much of life is spent within four walls. Here and in other regions of the world that have experienced extremely rapid sedentarisation and urbanisation, a break in the human-natural environment relationship is reflected in a loss of use and/or of understanding of lexemes and a change in describing time from narratives around events to calendrical dating. There are local attempts to revive the human-natural environment relationship: in Dhofar, through, for example, the Global Frankincense Alliance: www.globalfrankincensealliance.com, initiatives towards sustainable tourism, and annual courses on Mehri: Language and nature, run by the second author and Ali al-Mahri; in Qatar, various environmental experiments are currently underway in the coastal areas. ${ }^{1}$ These include planting qarm trees, and the

\footnotetext{
${ }^{1}$ Several agencies are collaborating to maintain and develop the coastal environment, namely the Supreme Council for Environment and Natural Reserves, and the Ministry of the Environment. The early efforts were practiced by the University of Qatar, as well as the companies Ras Gas, Qatar Petroleum, and Shell: Qatar second Human report (2009), pp. 86-87.
} 
establishment of six natural reserves for the protection of marine and wildlife in 2006, which increased to eight in 2009.1

This paper has addressed some of the ways in which the natural environment is reflected in the languages of our regions and in which a degradation of the environment can lead to a degradation of the lexis of a language. This initial paper will be followed up by further work examining the relationship between the local languages of our regions and the natural environment and considering means of revitalization of the languages, the ecosystems and the language-natural environment relationship.

\section{References}

[1] Alfaifi, A.H.J. (2016), Aspects of the morpho-syntax of the Faifa dialect of Saudi Arabia: A descriptive study, PhD thesis, Ulster University

[2] Al-Manji, S. \& J.C.E. Watson (2019), Climatic events and the role of narratives in resilience. Paper delivered at Symbiotic relationship between language and nature in Southern and Eastern Arabia workshop University of Leeds, 24-26 April 2019

[3] General Secretariat for Development Planning, 2009. Qatar second human development report, Advancing sustainable development, Doha.pp. 69-71

[4] Johnstone, T.M. (1981), Jibbāli Lexicon, Oxford, OUP

[5] Johnstone, T.M. (1987), Mehri Lexicon and English-Mehri Word-List, London, Routledge

[6] Macfarlane, R. (2015), Landmarks, London, Hamish Hamilton

[7] McKenzie, R. (1997), Downriver to here: Geographically spatial deictics in Aralle-Tabulahan (Sulawesi), in G. Senft (ed.) Referring to Space: Studies in Austronesian and Papuan languages, Oxford, Oxford University Press: 39-51

[8] Morris, M.J., J.C.E. Watson et al (2019), A Comparative Glossary of Modern South Arabian. Journal of Semitic Studies supplement, Oxford, Oxford University Press

[9] Palmer, B. (2002), Absolute spatial reference and the grammaticalisation of perceptually salient phenomena, in G. Bennardo, (ed.) Representing space in Oceania: Culture in language and mind, Canberra, Pacific Linguistics

[10] Rosenthal, M.J. (2014), When languages die, ecosystems often die with them. https://www.pri.org/stories/2014-07-15/when-languages-die-ecosystemsoften-die-them

[11] Rubin, A. (2010), The Mehri Language of Oman, Leiden, Brill

[12] Rubin, A. (2014), The Jibbali (Shahri) Language of Oman, Leiden, Brill

[13] Rubin, A. (2018), Omani Mehri: A new grammar with texts, Leiden, Brill

[14] Varisco, D. (1989), The Anwâ' Stars According to Abû Ishâq al-Zajjâj. Zeitschrift für Geschichte der Arabisch-Islamischen Wissenschaften 5: 145-166

\footnotetext{
${ }^{1}$ Planning Council, 2006. First Human development report, Doha, p. 55, and State of Qatar, Ministry of the Environment, http://www.moe.gov.qa.22/1/2011.
} 
[15] Varisco, D. (1991), The Origin of the Anwâ' in Arab Tradition. Studia Islamica 74: 5-28

[16] Varisco, D. (1997), Medieval Folk Astronomy and Agriculture in Arabia and the Yemen. Variorum Collected Studies. Hampshire, England: Ashgate Publishing Limited

[17] Watson, J.C.E. (1993), A Syntax of Șanৎānī Arabic, Wiesbaden, Harrassowitz

[18] Watson, J.C.E (2012), The Structure of Mehri, Wiesbaden, Harrassowitz

[19] Watson, J.C.E. \& Abdullah al-Mahri (2017), Language and nature in Dhofar. In: S. Bettega \& F. Gasparini (eds), Linguistic Studies in the Arabian Gulf: Quaderni di RiCOGNIZIONI. Rivisti di Lingue e Letterature straniere e Culture modern. 87103. University of Turin 